\title{
Lax Pragmatism and Magisterial Kant
}

\author{
Joseph Margolis
}

\section{(2) OpenEdition}

\section{Journals}

Electronic version

URL: http://journals.openedition.org/ejpap/2316

DOI: 10.4000/ejpap.2316

ISSN: 2036-4091

\section{Publisher}

Associazione Pragma

Electronic reference

Joseph Margolis, "Lax Pragmatism and Magisterial Kant", European Journal of Pragmatism and American Philosophy [Online], XIII-1 | 2021, Online since 02 April 2021, connection on 04 April 2021. URL: http://journals.openedition.org/ejpap/2316 ; DOI: https://doi.org/10.4000/ejpap.2316

This text was automatically generated on 4 April 2021.

\section{(c) (i) $\odot$

Author retains copyright and grants the European Journal of Pragmatism and American Philosophy right of first publication with the work simultaneously licensed under a Creative Commons AttributionNonCommercial-NoDerivatives 4.0 International License. 


\title{
Lax Pragmatism and Magisterial Kant
}

\author{
Joseph Margolis
}

\section{I.}

1 There is no easy way to defeat Kant's first Critique: Kant is indefatigable in rescuing his apparent lapses by means of overriding second thoughts and ingenuities. Nevertheless, he makes no sustained attempt to provide any evidentiary confirmation of his strongest claims in favor of necessary truths about exceptionless universal laws of nature and principles of Reason regarding the supposed cognitive fixities of the natural world: for instance in supplying an abundance of necessary synthetic a priori truths, apodictic judgments and the like. The fact is, there is more than prima facie evidence that all of Kant's specimens of such would-be truths (largely drawn from his reading of Newton's physics, as in the B Introduction to the first Critique) fail outright. They appear to be completely arbitrary; that's to say, true only by "stipulative" fiat $a$ posteriori (as C.I. Lewis affirms), or else they reduce harmlessly to analytic truths (see Lewis 1970). I leave all that aside as a provisional stalemate that may invite a stronger defense of realism than Kant's, if one can be found. If there is such an argument, it's likely to have been ignored by Rationalists. It would have had to reveal a substantial lapse on Kant's part that Kant's own doctrine could never recover convincingly: a conceptual option Kant's theory effectively precludes.

2 Now, I think there is such an option which standard empiricisms are aware of, but rarely draw on. Let me then offer some familiar philosophical ground - conceded by Kant - that invites the strategy I have in mind. There's little point in challenging Kant on merely textual or internal grounds: we require an entirely independent theory that, at its best, exposes the argumentative gap suggested. In that sense, the maneuver should be a simple matter. I find a particularly instructive clue in the Darwinian and neo-Darwinian continuum linking the higher mammals and the human primate. For, if these languageless creatures are actually intelligent - learning from experience, 
solving problems requiring a palpable measure of "reasoning," not to be confused with Kant's invention of Vernunft, the "faculty of Reason" (or "Rational cognition") - and if Vernunft entails a mastery of language, then, for one thing, there must be a "functionality" of mind that is a form of "thinking" or "reasoning" accessible to animals and maturing human infants (as well as adult human primates) that spontaneously qualifies the sensory sources of perceptual and experiential cognition, without any input from Vernunft; and, for another, the empirical component of cognition cannot be merely passive, must be cognitively adequate and effective in some degree due to the apt "functionality" of mind, that we may reasonably identify as "animal reasoning" (or thinking). I should add that I regard the contest between pragmatism and Kant's transcendentalism - addressed to the question-begging (cognitive) issues of First Philosophy - to count among the most telling confrontations of contemporary philosophy. Nevertheless, neither Kant's Vernunft (Reason: the wouldbe faculty of cognition, said to be addressed, transcendentally, to "what there is" in the actual world), nor the serviceable functionalities of animal "reasoning" (or thinking) are demonstrably designed to determine the validity of realist (unlanguaged) claims. Ultimately, the key issues of First Philosophy (epistemological or ontological) must be treated as no more than plausible conjectures, conditionally dependent on our best guesses regarding the would-be conduits to reality. But of course, that's to say that philosophy can never be satisfactorily completed.

Kant begins the B Introduction to the first Critique very nearly as an empiricist, but he overtakes the seeming initial autonomy of sensory experience at once by permitting experience to count as an admissible form of realist cognition only if (and where) it is constrained by the independent cognitive powers Kant assigns the faculty of Reason (Vernunft), that spontaneously provide objective and objectual form to (otherwise) passively streaming "sensible impressions." I shall depend largely on the thrust of the following two passages from the first Critique: one from the B Introduction; the other from the section titled, "On the [Transcendental] Deduction of the Pure Concepts of the Understanding" - that's to say, categories of Reason (Vernunft) that must be in play before any pertinent sensory episode occurs. I take both passages to be self-defeating. The first is altogether too vague to be trusted:

There is no doubt whatever, [Kant begins] that all our cognition begins with experience [...]. But although all our cognition commences with experience, yet it does not on that account all arise from experience. For it could well be that even our experiential cognition is a composite of that which we receive through impressions and that which our own cognitive faculty (merely prompted by sensible impressions) provides out of itself, which addition we cannot distinguish from that fundamental material until long practice has made us attentive to it [...]. (B1-2)

But, of course, this fails utterly to explain how the entire table of discursive categories is originally supplied - say, to infant primates, who are about to learn their home language. It seems as if they must begin with sensory concepts that exhibit a suitable affinity with the discursive concepts they eventually master. Which is to say, there must be a functional form of "reasoning" or "thinking" accessible to advanced animal species as well as human infants, if we are to account for the infants' normal feat - a feat altogether different from the work of Vernunft (Reason), putatively the facultative power of discursive cognition. At the very least, the initial sensory streaming cannot be entirely passive. On the contrary, Vernunft itself seems to depend on forms of elementary "reasoning" (inference, for instance) that is already inseparable from 
experientially grounded animal intelligence. I take this to be an essential lesson of Darwinian and post-Darwinian evolution. In any event, in their very different ways, both Darwin and Kant scant the same question.

The second passage reads as follows:

Now we already have two sorts of concepts of an entirely different kind, which yet agree with each other in that they both relate objects completely a priori, namely the concepts of space and time, as forms of sensibility, and the categories, as concepts of the understanding. (B117/A85)

6 I cannot see why Kant supposed his choice of a priori necessity was more compelling than a robust form of contingent empirical cognition suitably fitted to animal intelligence, without any need for discursive concepts. (What, for instance, is the meaning of "prompted" in the first passage?)

7 Here's a first consideration. If the original streaming of "sensible impressions" is essentially formless, apart from the forms provided by space and time, then, given the continuum of animal and human perception and experience offered (say) in Darwinian and post-Darwinian evolution, some sort of transcendental apriorism may have to be conceded to function realistically among languageless animals; and if that's refused, (say) on the grounds that any pertinent a priori presupposes a mastery of language and the use of discursive concepts, then there simply are no intelligent animals to be found. But that's preposterous. I agree with the drift of evolutionism (and Aristotle) to the effect that there must be perceptual concepts distinct from discursive concepts (though suitably akin to the latter), if we are to concede that human infants begin to grasp objectual structures before they have actually mastered a workable language. I'm inclined to think that spatial and temporal structures tend to be inseparable from standard perceptual distinctions that include but are not restricted to anything like perceptible macroscopic objects. The archic powers (of the would-be cognitive faculty, Vernunft) are simply circularly "deduced."

This suggests a second, more searching consideration. If there are intelligent animals capable of realist discrimination - despite lacking language and discursive concepts (bears fishing for salmon, say) - then there must be an enabling form of "reasoning" (capable of a range of inference, for instance solving problems, learning from experience) that standardly accompanies empirical cognition without requiring transcendental powers of any kind - that nonetheless extends to perceptual space and time (not merely geometric) - then Kant is defeated by the facts of animal life. Just think of a housecat learning to unlatch a kitchen cabinet or a border collie rounding up stray sheep. Kant introduces Reason (Vernunft) as the executive (transcendental) "faculty of cognition" possessed exclusively by enlanguaged selves. Kant makes the double assumption that the separate, completely independent contributions of Reason (or thought) and passively received "sensory impressions" (or sensibility) must, somehow, mesh correctly if it is to yield empirical cognition; and that, at the same time, Vernunft must already possess the requisite concepts and categories before and entirely independently of the sensory event itself. But I cannot see how that could possibly work, if Reason were unable to construct its objectual concepts by abstracting pertinent sensory features from the independent sensory manifold. of course, in that case, the transcendental would (as I say) depend on the sensory itself - which Kant could not possibly concede. 
Reason, I say, takes many forms: some cannot be transcendental. Kant invents Vernunft as the decisive "faculty of cognition," but it fails utterly. All of Kant's transcendental specimens fail. I remind you that there are no assuredly confirmed (or confirmable) synthetic a priori truths, exceptionlessly universal laws of nature, or apodicticities. Reason, in the form of Vernunft, cannot be more than a fiction - specifically, a fictive cognitive faculty. The trouble is, Kant has no criterially pertinent account of the signs of cognitive realism - or of any Idealist construction of an enabling realism - unless its sheer presence and self-evident adequacy cannot be contested. But that can't be good enough. (I'll come shortly to an empirical - in fact, a pragmatist - alternative.) For the moment I offer the enabling distinction between a would-be Rationalist faculty (the transcendental faculty of cognition) and mundane (empirical or sensory) reasoning (already introduced) as a distinct functionality of mind that, commonly entwined with what is sensorily "given" in what we (and Kant) call experience, is already capable of focusing something of the significance of what is thus given. (The argument applies to animals and human infants as well, though they lack language and discursive concepts.) Kant's facultative claim defeats itself, then, if indeed there are no demonstrable fixities of the sorts Kant imagines. (A Kantian faculty seems to be inherently transcendental, whereas ordinary reasoning is simply a contingent mode of the mind's functioning - with no particular privilege regarding knowledge of the actual world.) My treatment of the distinction between "faculty" and "functionality" is little more than a gloss on Reichenbach's treatment of the matter (Reichenbach 1956: Part One). Still, Kant seems to take it for granted that if we accept his transcendental premise, the realism issue will have been settled!

Now, the sparest empiricist - in fact, an important element in the pragmatist conception of empirical knowledge provides an extremely plausible approach to cognitive realism, without any abstruse enabling machinery from the would-be "faculty of Reason." It's perfectly reasonable to separate the would-be transcendental powers of the faculty of Reason (Vernunft) from the empirical or instrumental functionalities of the mind that, even in the unlanguaged animal world, can be strengthened and improved. It's only that I deem transcendental Vernunft to be entirely fictional or arbitrary and indemonstrable. Advanced animals lack the discursive concepts of cognitive realism and the ability to report their inner mental states - hence they have no conscious awareness of their own facultative powers. But then, in Kant's apparent commitment, they could not survive if they required the powers of transcendental Reason. (Kant cannot, then, accommodate animal intelligence without a radical change of theory.)

There is a distinctive perceptual or experiential "duality" that runs through human and much of animal experience (along promisingly cognate lines), that seems all but assuredly linked to an effective realism, conscious or not. I mean the spontaneous ("given") "appearings-of-the-world-to-us" and the cognate "appeareds" (macroscopic objects, say) that tend to "appear" reliably and recurrently among our interpretively transient "appearings." These are hardly contrived! It's reasonable to suppose that the executive brain embeds this automatic advantage (by nonconscious means) in our perceptions, so that we need not stray too far to be realistically (but no more than approximatively) oriented empirically. Pragmatism itself is, quite laxly, "instrumentalist," open-ended, incompletable - though seemingly adequately revisable (where needed) for ordinary life. In a word, Kant misrepresents the realism of animal and human life. It's the enabling structures and processes of the sensory modalities 
(sight and hearing, preeminently, functioning through the eyes and ears) that justify the assumption of their being "faculties of cognition" - not Vernunft, which produces no suitably parallel duality. If we confine ourselves to empirical resources, then I should say the perceptual modalities are indeed the only true faculties of cognition (among animals and humans, alike), although they cannot service transcendental powers. Among humans, they service only the unassuming mundanities of a makeshift pragmatism - which accommodate whatever precision or changes of conviction the human race requires. The argument actually seems to have located a mortal weakness in Kant's Critique that I've been seeking: our ignorance of the mental life of animals. But it also savages the whole of transcendentalism. Is that acceptable?

12 I should perhaps add that First Philosophy is, in good part, a matter of conceptual fashion. I have been attracted by what may be called an "imaginary," the would-be single pendulum swing from Parmenides to pragmatism, a sweep from fixity to flux so that the weakness of Kant's entire vernünftig undertaking will have been rendered vulnerable as a consequence of the accumulating failures of Rationalism and transcendentalism. Of course, Kant has had his inning: there are no ontic or epistemic fixities of Kant's persuasion. Realism itself is dependent on a conjecture tethered to existential history.

\section{II.}

I trust it's clear that, admitting Kant's immense importance and influence and the ineliminable petitios of First Philosophy, a viable empiricism pretty well requires the defeat of Kant's transcendentalism. Realism, the cognizability of the actual world, cannot be a negligible matter; but neither can it be more than a dependent conjecture. That's to say, from the pragmatist point of view, it's not necessary (in fact, it's impossible) to prove - beyond a reasonable uncertainty - that we assuredly satisfy the conditions of objective cognition. Of course, we do not, but then we need not. In fact, I'm prepared to say, borrowing John Dewey's well-known and well-conceived epistemic compromise ("warranted assertibility"), that we are able to reduce doubt about the objectivity of our cognitive beliefs without actually attempting to reach indubitable truth; or, indeed, by electing a Peircean "abduction," which, in my opinion, converges satisfactorily with Dewey's sensible qualification. Empirically, then, the sum total of the perceptual conditions of realism cannot be completely satisfied: they cannot even be completely known. Kant, of course, cannot accept any such lacuna. But he neglects the existential role of history (hence, also, a perfectly benign skepticism - the mate of whatever we take to be the source of empirical knowledge) and the evolution of novel experiential episodes. In this sense, the defeat of Kant's transcendental Reason, or the provision of a Peircean "abduction," yields a second gain: a gathering sense of the instrumental aptness of an incomplete set of the enabling conditions of realism among our mundane concerns. We proceed (empirically), by corrective guesses and a sense of approximative adequacy: that is, realism remains conjectural, but revisable in sensory ways.

14 I see in this the incipient endorsement of another important empirically conceived liberty: namely, the apt analysis, appreciation and interpretation of the enlanguaged artifacts of the human world. Here, the connective - "civilizational" - process rests with its ethos more than its logic, though it cannot fail to apply its cognitive resources 
supportively. It seeks to penetrate the holist "meaning" and significance of human life - again, constantly evolving, continually novel, but incompleteable nonetheless. It's an extraordinary fact, but true enough, that Darwin utterly fails to examine the (thus far) final, most important, completely unique phase of human evolution - the invention and mastery of natural language (and its accompanying cultures) and the significance of the radical change in evolution itself; the appearance of a hybridized process that entwines biochemical and enlanguaged cultural forces in accounting for the self-transformation of primate into self or person. The linkage is a loose one, but firm enough - the collective effort of humanity to understand the evolving nature and behavior of actual human life. The holism of the effort draws very naturally from the remarkable feat of sharing a public language - incorporating even the complex forms of serial bilingualism or pluralism, globally extended. This is the common space of human labor and liberty: the creation, production, enactment, and expression of all that belongs to civilizational life. But then the discursive is itself a thoroughly dependent innovation.

relates to enlangauged cultural artifacts, I say, has a distinctive kind of meaning, significance, signification, semiotic import, or the like, which I call "Intentionality" (written with capital "I"). Its characteristic analysis I call "interpretation," the detection or inventive construal of its discursive meaning or significance. The mode of understanding Intentionality is basically empirically imaginative rather than assuredly cognitive in the rationalist sense mentioned in section I; although interpreting societies tend to adopt (what I call) a sittlich norm or norms of meaning and significance (plausible beliefs) characteristically less than objective truth - but no longer partitioned ("compartmentalized," to use Dewey's derogatory term), however restricted to something akin to "warranted assertibility" which reaches to an acceptable measure of trustworthy belief but not to confirmably fixed or apodictic truth. There you have the civilizational (or geistlich) sense of the pragmatist "aesthetic," which provides for the unrestricted (pluralistic) interplay of appreciative and interpretive concepts, now engaging the "imaginary" holism of a civilization or historied Lebensform.

I'm afraid I regard Kant's treatment of the aesthetic judgment of beauty (in the third Critique) a complete disaster. But, in assigning a good part of the aesthetic use of the "Intentional" to the imagination, I mean to signify that Intentional interpretation applies, discursively, to any and every pertinently enlanguaged space, "civilizationally" - that is, integrally, collectively, overlappingly, consensually - to engage politics, morality, religion, medicine, education, sports, manufacture, the law, the arts, practical life. It's a well-known commonplace that the interpretation of modern painting cannot be productively "compartmentalized" (Dewey's term) as strictly autonomous disciplines or idioms, as between the aesthetic and the political. Every viable predicable acquires affinities (both lax and strict) across the entire unity that is a society's collective life (see, for instance, de Duve 2018: 97-8).

One of the cleverest, certainly one of the most celebrated (and often demoted) exemplars of the mutual dependence of the aesthetic and the political in the multifaceted revolution against the Beaux Arts System in mid-nineteenth-century France is still Manet's "Luncheon on the Grass" (1863) (see Bourdieu 2017). De Duve makes the interesting suggestion (in Kant's behalf, in the third Critique) that "The only true art would be the art of living. The good and the beautiful would [then] be one" (Kant 1999: 97) - though de Duve rightly warns us that these two predicables are not the same. This 
catches up the import of the phrasing, "le sens de la famille," which is meant (metaphorically) to explain Kant's view of mankind as an extended family. If we read this literally, then it accords as well with the sense in, say, Abraham Lincoln's Emancipation Proclamation (which appeared about the time of Manet's painting), which could also count as both an aesthetic gesture and an unexpected political commitment (one can almost imagine Lincoln murmuring to himself: "Beautiful," which is to say, opposing Kant, that a discursive explanation would be entirely welcome). But just as this connection occurred to me, Alexei Navalny, Vladimir Putin's best-known political critic, returned to Russia from his German hospital (where he recovered from a near-fatal poisoning) to surrender to the Russian authorities. I would say that that was similarly brilliant, courageous, and thoroughly beautiful, though I would not think, in saying so, that I was "entitled" (in Kant's sense) to count on universal accord. Intentional interpretation is hospitable, for entirely different reasons, to both relativistic and pluralistic forms of holism.

18 The failure of the archic (the transcendental, say) in the natural world - in First Philosophy, enlanguaged human space - may be the single most decisive philosophical discovery that may be claimed, in favoring the primacy of pragmatism's empirical resources over Kant's arbitrary transcendentalism. There are, as I say, no synthetic $a$ priori necessary truths, no apodicticities. Hence, Reason (Vernunft) cannot be a cognitive faculty, in any sense that rivals the rightful claims of sensory perception (to include, integrally, animal forms of inference or induction or the like). As I've argued, sensory perception and experience appear to include a variety of elementary forms of thinking or "reasoning" (functionalities of mind, let us say) that make it possible for the higher languageless animals to be intelligent - to learn from experience, for instance. It's the continuum of the animal and the human in this regard that Darwinian evolution vouchsafes (that Kant all but neglects), although it's also true that Darwin fails to grasp the cultural marvel of discursive understanding. But what is Kant without the transcendental? Nothing but "a somewhat confused pragmatist," Peirce affirms! (See Collected Papers, 5.525). Kant's theory of the sensory as completely passive and "unthinking" is entirely off the mark. It's surely inappropriate to posit, as one's most important cognitive source, a would-be faculty that cannot be straightforwardly confirmed.

19 Apart from the formal sciences, truth, among pragmatists, is never quite secure: Dewey favors reasonable belief over questionably assured truth, or perhaps, confirmation is itself somewhat honorific - effectively, a risked conjecture. This is the sense in which Peircean "abduction" and Deweyan "warranted assertibility" merge or converge as a shared form of improvisational confidence about the provisional adequacy of what Dewey names "instrumentalism," a would-be felicitous guess at what serves our practical needs and interests for the occasion: ultimately, a form of "learned ignorance" on the part of savvy investigators likely to bring us close to an enabling belief short of assured truth.

20 If we press the point, pragmatism will be viewed as decidedly free-wheeling: erroneous conjectures may even, on occasion, be more rewarding than mundane truisms. In any case, they will be continually replaced. There is no science of science to gainsay the practice. It's in this sense that I view Nancy Cartwright's and Ian Hacking's experimental methods as somewhat akin to a Peircean abduction or a deliberate reversal of the standard unity-of-science policy. In any active discipline - politics, 
medicine, education - history and actual discovery affect our future methodological guesses. It's the holism of a collective society or culture or Lebensform or linguistic practice that takes command: the "compartmentalization" of historied disciplines collapses; there is no assured disjunction, say, between the articulation of the aesthetic and the political. Interpretation tests its own disposition; we find ourselves confronted by the rush of new objects, new data, new linkages, new meanings involving the human world. At the very least, these events seek a new (approximative) "sittlich" site of societal life, as they evolve; Kant's aesthetic "entitlement" to universal agreement regarding beauty becomes utterly pointless. The new "rule" is ouverture, the democratization of taste - as hospitable to banalities as to high art. And yet, I find a distinction of considerable importance to be salvaged here, that begins to find its own double nascent in creativity and mundane praxis, the very poles of human agency. I'm referring once again (obliquely) to the "duality" of "appearings" and "objects" that "appear" in such "appearings." I suggest that every responsible cognitive realism requires such a duality - in order (at the very least) to distinguish the apparent and the actual. (I claim, of course, that Kant fails us here.) Duality affords the best clue I can think of that provides a structural sense of how to approach the realism issue; and, of course, it clearly favors some form of empiricism or pragmatism. It also makes sense of the Darwinian continuum and the intelligence of animals, which rationalism usually fails to address.

21 I've distinguished lightly between Franz Brentano's treatment of the "intentional" and my own conception of "Intentionality," which favors different senses of "aboutness" (cf. Margolis 1995). Brentano favors a narrowly defined mentalistic puzzle. I frankly pirate the term to mark the search for the approximative (referential) aboutness of the sittlich site of any enlanguaged or language-bound utterance that invites or requires interpretation in a culturally requisite sense: that's to say, an Intentional interpretation of the import or significance (the semiotic "aboutness" - if you wish) of what one deems to be "intended" by one's choice of a suitable sittlich site. For instance, Wordsworth's well-known Lucy poem, which grieves over the death of the poet's beloved, is not inaptly thought to be centered on the import of a dehumanized physics. In that sense, my use of "intentional" searches for those parts of the would-be sittlich core of the life of a collective society and its perceived spirit, which centers the intended or completed utterance perspicuously. Brentano's "intentional" tends to be broadly referential. But then, ideally, the "Intentional" (with capital "I") offers a creative interpretation of (about) what the "intentional" (in my contrived sense) takes the utterance to be about, referentially. Ineluctably, the interpretation affects the meaning of the sittlich core. I intend this formulation as the merest makeshift, to afford a reasonable sense of legible order under minimal (largely improvisational, experimental) constraints. In that sense, Intentionality favors both pluralism and relativism.

22 I remind you that there is no art or politics without language; no history or morality or normativity or objects that manifest interpretable meaning. All of these distinctions are thoroughly artifactual: they have no cognate sources in mere physical nature. They escape sheer arbitrariness, however, by the iterability of artifactual differences. In Kant, in the Opus postumum, they already take the form of imperatives - which is to say, they appear as discoveries or revelations of archic power! of course, they were already thus approached by Hammurabi. The arts and politics collect the births and deaths of all such transformations, Intentionally; and, thus conceptually prepared, we turn from 
one would-be sittlich station to another. Historied consensus collects these judgments in an acceptable narrative. Almost no one now dwells on the sun's mortality! Thus construed, Intentionality is no less than the most ineliminable part of the species' need to understand itself. We lack a natural or essential telos. But we have an endless appetite for surrogates of our own invention, which is never quite adequately appeased but which defines our purpose. The only alternative (perhaps) is to anticipate another meteor to clear the planet for other species, other races. Intentionality is little more than mortality focused in distraction. The argument spills over into the study of physical nature itself, but now under the executive questions of human possibilities which we have yet to capture. Perhaps a threat from outer space would...?

I leave the matter unresolved: it's unresolvable. It's the endless innovation of the future that we must heed: it replaces every presumptive telos, as we survive. In that obvious sense, we come to understand the diverse and changeable unity of the human narrative. That's to say, its fearsome and contingent mystery.

\section{BIBLIOGRAPHY}

BOURDIEU Pierre, (2017), Manet: A Symbolic Revolution, Wiley.

DE DUVE Thierry, (2018), Aesthetics at Large, Vol. 1: Art, Ethics, Politics, Chicago, Chicago University

Press.

KANT Immanuel, (1999), Critique of Pure Reason, translated by Guyer and Wood, Cambridge-New York-Melbourne-Madrid, Cambridge University Press.

LEWIS Clarence Irving, (1970), “A Pragmatic Conception of the A Priori,” in Collected Papers of

Clarence Irving Lewis, Standford, Standford University Press, 231-9.

MARGOLIS Joseph, (1995), Historied Thought, Constructed World, Berkeley, CA, University of California Press.

PEIRCE Charles Sanders, (1931-1958), Collected Papers, Cambridge, Mass., Harvard University Press. REICHENBACH Hans, (1956), The Rise of Scientific Philosophy, Berkeley-Los Angeles-London, University of California Press.

\section{ABSTRACTS}

This paper develops a criticism of Kant's transcendentalism, claiming that his idea of reason fails to take into account the Darwinian continuum linking higher mammals and human primates. At the same time, Kant's ontology and epistemology fail to consider the fact that humans are the product of the contingent yet irreversible linguistic, cultural, and Intentional (written with capital "I") configuration of their form of life. The author favors pragmatism as a viable alternative, and draws upon John Dewey's epistemic compromise ("warranted assertibility"), suggesting that we can reduce doubt about the objectivity of our cognitive beliefs without 
actually attempting to reach indubitable truth. On these grounds, the paper argues against the "compartmentalization" of art with respect to politics, morality, and normativity.

\section{AUTHOR}

JOSEPH MARGOLIS

Temple University

jmargo01[at]temple.edu 